\title{
Types of Physical Exercise Training for COPD Patients
}

\author{
R. Martín-Valero, A. I. Cuesta-Vargas and M. T. Labajos-Manzanares \\ School of Nursing, Physiotherapy, Podiatry and Occupational Therapy \\ Psyquiatry and Physiotherapy Department \\ Málaga University \\ Spain
}

\section{Introduction}

Pulmonary diseases are increasingly important causes of morbidity and mortality in the modern world (Ries et al., 2007). Chronic obstructive pulmonary disease (COPD) is the most common chronic lung disease, and a major cause of lung-related death and disability (Fishman, 2008). COPD is characterized by chronic airflow limitation, progressive and largely irreversible, associated with an abnormal inflammatory reaction (Ancochea Bermúdez et al., 2009). COPD is very disabling and features extra-pulmonary manifestations, but it can be prevented and treated.

The disease is diagnosed by a clinical history based on the combination of history, physical examination and confirmation of the presence of airflow obstruction with the use of spirometry (Figure 1 Spirometry). Spirometric assessment is performed according to the guidelines of the American Thoracic Society (ATS) (Laszlo, 2006). The technician asks the subjects three exhaling exercises and the best is used for the analysis (Miller et al., 2005). If the Tiffenau rate (value of $\mathrm{FEV}_{1} / \mathrm{FVC}$ ) is less than seventy percent, COPD exists (Global initiative for chronic obstructive lung disease [GOLD], 2010). Smoking is the major risk factor for the disease (Hilberink et al. 2011).

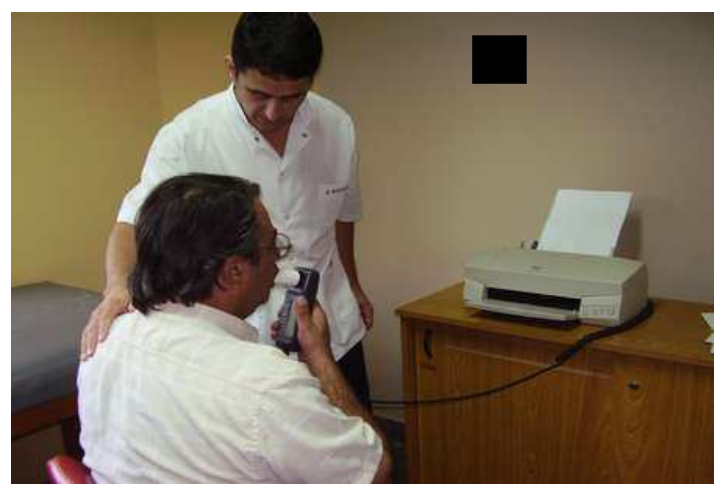

Fig. 1. Spirometry 
The most common symptoms of COPD are breathlessness, chronic cough, wheezing, sputum production, recurrent respiratory infection may be associated with some of the following systematic effects such as undernourishment, weight loss, exercise limitation and muscle weakness $(G O L D, 2010)$. Knowledge regarding the disturbance of muscle function that occurs in patients with COPD is continuously increasing. Initially muscular dysfunction was considered to be a self-limiting disease resulting from inactivity and lack of exercise. However, recent studies have shown that in addition to this factor, peripheral muscles such as the quadriceps seem to have some type of myopathy (Couillard \& Prefaut, 2005). Although the presence of myopathy is still being debated, there is some evidence pointing to myopathy associated with oxidative stress (Rabinovich et al., 2001). Recent studies in COPD have highlighted the role of the ubiquitine proteasome system in the breakdown of skeletal muscle protein in COPD patients. Malfunction of the mitochondria has also recently been identified in these patients (Rabinovich \& Vilaro, 2010).

COPD is a major cause of disability and mortality worldwide and the prevalence increases with age. COPD will increase by more than thirty percent in the next ten years, if the population does not cut down smoking (Ancochea Bermúdez et al., 2009). Actually, due to high prevalence, associated to high morbilidity, economic and social cost COPD is a major health problem (Ramsey \& Sullivan, 2003; Sullivan, Ramsey, \& Lee, 2000). COPD is not curable, but treatments can help to control symptoms and improve quality of life of patients. It is necessary to reduce risk factors such as smoking and physical inactivity (GOLD, 2010).

Many people suffer from COPD for years and die prematurely of it or its complications. The goals of the Global Initiative for Chronic Obstructive Lung Disease (GOLD) (Rabe et al., 2007) are to improve prevention and management of COPD through a concerted worldwide effort of people involved in all facets of health care and health care policy, and to encourage an expanded level of research interest in this highly prevalent disease. The GOLD report separates COPD patients into the four different stages (figure 2) $(G O L D, 2010)$.

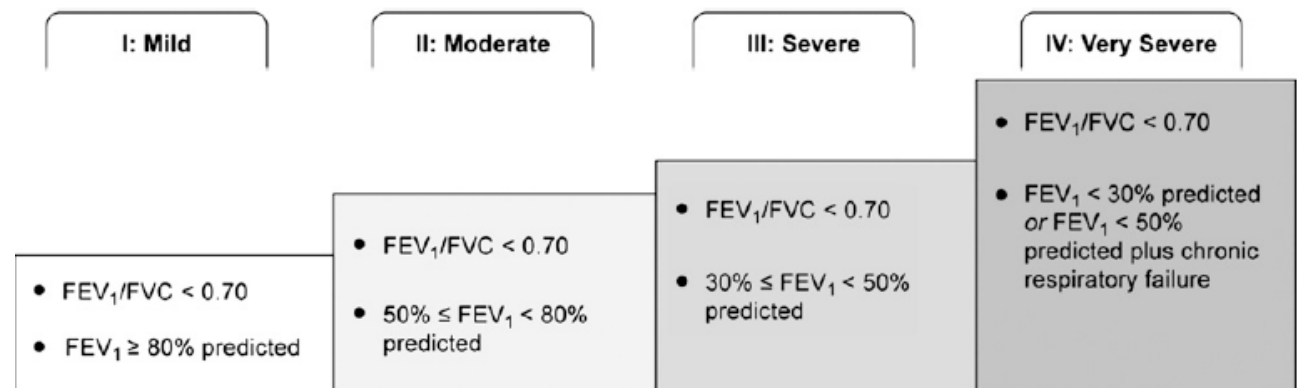

Fig. 2. Stages for Chronic Obstructive Pulmonary Disease

Pulmonary rehabilitation has emerged as a recommended standard of care for patients with chronic lung disease based on a growing body of scientific evidence. The American Thoracic Society and European Respiratory Society (ATS /ERS) published a document in 2006 defining respiratory rehabilitation as "a multidisciplinary and comprehensive intervention has proved effective from the perspective of evidence-based medicine for patients with chronic respiratory diseases who are symptomatic and often have decreased daily life activities. Integrated into individualized treatment of the patient, pulmonary rehabilitation is designed to reduce 
symptoms, optimize functional status, increase participation, and reduce health-care costs by stabilizing or reversing systemic manifestations of the disease" (Nici et al., 2006). This definition focuses on three aspects of successful rehabilitation: a multidisciplinary approach; an individualized program; tailored to the patient's needs; and attention to physical psychological and social functioning (Ries, 2008). Not forgetting a primary goal of rehabilitation interventions for people with COPD is to optimize function (Nici et al., 2006).

The components of multidisciplinary respiratory rehabilitation programs include education of patients and their families, chest physiotherapy, muscle training, the emotional support, nutritional support, occupational therapy (Ries et al., 2007). Physiotherapy consists of various phases of treatment (exercise training, peripheral and respiratory muscle training, and breathing exercises) that are considered cornerstones of the physiotherapeutic intervention (Langer et al., 2009). Also consider patients that are incorporated into a respiratory rehabilitation program must have an optimal pharmacological treatment, although not analyzed in this chapter.

There is no consensus of opinion regarding the optimal duration of the pulmonary rehabilitation intervention (Ries et al., 2007). The duration depends on changes in the patient's lifestyle. A number of external factors also influence program duration including health-care systems and reimbursement policies, access to programs, level of functional disability, health-care provider referral patterns, and the ability of individual patients to make progress toward treatment goals.

Few clinical trials have focused on the impact of program duration on rehabilitation outcomes, but existing data suggest that gains in exercise tolerance may be greater following longer programs (Berry et al., 2003; Foy, Rejeski, Berry, Zaccaro, \& Woodard, 2001; Green, Singh, Williams, \& Morgan, 2001; Troosters, Gosselink, \& Decramer, 2000). Besides Verrill et al. (2005) demonstrated that patients achieved significant gains in exercise tolerance in the six minute walk distance, after twelve weeks of pulmonary rehabilitation. However, in an older trial Wijkstra et al. (1995) showed that there was no difference noted between groups in the magnitude of gains in the six minute walk distance for patients who underwent 18 months and three months of home-based rehabilitation.

Moreover, although some studies suggest that the duration of the pulmonary rehabilitation program has an impact on exercise tolerance improvement, it is not clear that other outcomes such as health status or dyspnea are similarly affected by program duration (Ries et al., 2007). Thus, given the variations found in types of rehabilitation programs and content as on duration (Clini et al., 2001). Besides the differences found in clinical study design, patient populations, health systems in different countries, program location, and program content.

The purpose of this literature review is to compare the effectiveness of various exercises training programmes in the rehabilitation of COPD patients. This study analyzes the different types of aerobic exercises that are carried out with different intensities, doses and frequencies.

\section{Exploratory testing}

The chronic symptoms of COPD (cough, expectoration, wheezing, dyspnea and exercise tolerance) are the major factors responsible for altering the relationship between health and 
quality of life. Studies of health-related quality of life (HRQoL) in patients with COPD with varying degrees of severity have consistently shown that patients have significant decrements in HRQoL (Okubadejo, Jones, \& Wedzicha, 1996; Schrier, Dekker, Kaptein, \& Dijkman, 1990). Therefore, HRQoL is an important clinical outcome in COPD. The Chronic Respiratory Disease Questionnaire (CRQ) (Guyatt, Berman, Townsend, Pugsley, \& Chambers, 1987) and St George's Respirtory Questionnaire (SGRQ) (Jones, Quirk, Baveystock, \& Littlejohns, 1992; Jones, 2001) are the main questionnaires used to measure the quality of life in COPD patients.

The evidence-based clinical practice guidelines document concluded that there was a strong level of type A evidence, that Pulmonary Rehabilitation Programmes (PRP) improve the symptom of dyspnea in patients with COPD with a strong level of type A evidence (Jones, 2002). Dyspnea is a sensation of respiratory discomfort and the evaluation of the degree of dyspnea provides an independent dimension that is not provided by pulmonary function tests or by measuring dyspnea in an exercise laboratory. So, dyspnea is a main symptom associated with exercise performance and, therefore, quality of life. One of the major goals of COPD treatment is a reduction in dyspnea. The severity of the disease can be determined by the intensity of dyspnea (Camargo \& Pereira, 2010). The severity of COPD is habitually classified by forced expiratory volume in the first second $\left(\mathrm{FEV}_{1}\right)$ after bronchodilator use (Rabe et al., 2007). Various instruments are available to measure the degree of dyspnea during exercise; the modified Medical Research Council (mMRC) dyspnea scale is the most used (Barbera et al., 2001). The mMRC has five levels that increase with the level of activity in which dyspnea appears. It assesses common tasks the patient can develop without displaying dyspnea. Levels of Dyspnea are graded as follows. Grade 0: "I only get breathless with strenuous exercise"; grade 1: "I get short of breath when hurrying or walking up a slight hill"; grade 2: "I walk slower than people of the same age because of breathlessness or have to stop for breath when walking at my own pace"; grade 3: "I stop for breath after walking 100 yards or after a few minutes"; grade 4: "I am too breathless to leave the house".

The mMRC was unidimensional, to overcome this limitation; Mahler (Mahler, Mejia-Alfaro, Ward, \& Baird, 2001) designed the index known as the Baseline Dyspnea Index (BDT), which was later supplemented with the Transitional Dyspnea Index (TDI). BDT analyzes dyspnea from a triple perspective; the difficulty of the task, magnitude of effort and functional impairment, each of the sections will be assessed from 0 (severe) to 4 (none), so total amount can range between 0 and 12 (Mahler, 2006). TDI assessed changes over time compared to baseline (BDI), the changes in each of the three sections are measured between -3 and +3 . Therefore, the total score can be between +9 and -9 . A score of 0 indicates no changes have occurred, while -9 is very negative result (Sobradillo et al., 1999). Both multidimensional scales, BDT and TDI, are clinical instruments that can be used during cardiopulmonary exercise testing for clinical and research purposes. Besides, Borg et al., (Borg, Borg, Larsson, Letzter, \& Sundblad, 2010) described the matching of the increase in dyspnea related to ventilation and oxygen consumption in exercise.

In a review of application of dyspnea and quality of life scales in COPD, it was concluded that a unidimensional scale can be used if applied in conjunction with specific quality of life scales. Alternatively, a multidimensional scale, which correlates better with quality of life, can be used (Bausewein, Farquhar, Booth, Gysels, \& Higginson, 2007). Consequently, multidimensional clinical instruments were developed in order to provide a more 
comprehensive assessment of the severity of dyspnea, combined with the Chronic Respiratory Disease Questionnaire (CRQ) incorporates five physical activities that are specific for individual patients (Guyatt et al., 1987). These instruments have been shown to be valid, reliable, and responsive (Reda, Kotz, Kocks, Wesseling, \& van Schayck, 2010).

In 2004, Celli et al. created a mortality prediction index, known as the BODE index. It encompassed the body mass index (B), the degree of airflow obstruction as expressed by the $\mathrm{FEV}_{1}(\mathrm{O})$, dyspnea with the modified medical research council (D), and exercise (E) measured with six-minute walk distance (Table 1 Variables and point value used for the computation of BODE index) data adaptated from Celli et al. (2004). The cut-off values for the assignment of points are shown for each variable. ${ }^{*} \mathrm{The}^{\mathrm{FEV}} \mathrm{F}_{1}$ categories were identified by the American Thoracic Society (1995). $†$ Scored on the modified Medical Research Council (mMRC) dyspnea scale can range from 0 to 4 , with a score of 4 indicating that the patient is too breathless to leave the house or becomes breathless when dressing or undressing.

\begin{tabular}{|c|c|c|c|c|}
\hline \multirow{2}{*}{ Variables } & \multicolumn{4}{|c|}{ Points on BODE index } \\
\hline & 0 & 1 & 2 & 3 \\
\hline $\mathrm{FEV}_{1} \%$ of predicted & $\geq 65$ & $50-64$ & $36-49$ & $\leq 35$ \\
\hline Six-minute walk distance (m) & $\geq 350$ & $250-349$ & $150-249$ & $\leq 149$ \\
\hline MRC dyspnea score $^{\dagger}$ & $0-1$ & 2 & 3 & 4 \\
\hline Body mass index $\left(\mathrm{kg} / \mathrm{m}^{2}\right)$ & $>21$ & $\leq 21$ & & \\
\hline
\end{tabular}

Table 1. Variables and point value used for the computation of BODE index, adapted from Celli et al. (2004)

The BODE index is a multidimensional classification system that systemically determines the degree of mortality in individuals with COPD, that provides useful prognostic information in patients with COPD and might be able to measure health status. However, it is unknown whether the BODE index is a sensitive tool for predicting the impact of quality of life in such patients. Araujo (Araujo \& Holanda, 2010) found correlations between the BODE index scores and all of the CRQ domains in COPD patients. Moreover, there are studies where patients who moved from moderate to high physical activity improved their SGRQ scores by 18.4 and their CRQ scores by 14.8 (Esteban et al., 2010).

Over recent decades, several organizations have championed pulmonary rehabilitation and developed comprehensive statements, practice guidelines, and evidence-based guidelines (Ries, 2008), however there are differences about how assessment of severity of disease. The 2010 NICE Guidelines defended that multidimensional assessment tool (BODE index) is a better predictor of mortality and exacerbation rate than $\mathrm{FEV}_{1}$ alone (Gruffydd-Jones \& Loveridge, 2011).

Exercise testing is frequently used in the clinical evaluation of patients with COPD to evaluate the functional impact of a treatment (American Thoracic Society \& American College of Chest Physicians, 2003). Exercise testing is a useful evaluative tool, allowing standardized measurement of exertional dispnea and exercise tolerance (GOLD, 2010). There is, however, no consensus regarding which exercise testing protocol should be used for this application (Pepin, Saey, Whittom, LeBlanc, \& Maltais, 2005). A research indicated that walking, as performed in the endurance shuttle walk, is sensitive to detect changes in exercise performance after bronchodilation (Pepin et al., 2005). Besides Pepin et al. (2007) 
indicate that the response of the 6MWT test is not sensitive to change and may not be appropriate for an assessment tool. Another research also suggests that the endurance shuttle walk is more responsive to the effects of pulmonary rehabilitation than the 6MWT for detecting changes in exercise performance following broncholdilations (Eaton, Young, Nicol, \& Kolbe, 2006). Together, these findings provide growing support for the use of the endurance shuttle walk as an evaluative tool to monitor response to treatment to COPD.

The six minute walk test (6MWT) is used in order to determine the six-minute walk distance (6MWD), which correlates with the performance of activities of daily living in patients with COPD (ATS Committee on Proficiency Standards for Clinical Pulmonary Function Laboratories, 2002; Brooks, Solway, \& Gibbons, 2003). The 6MWT measures the global and integrated responses of all organ systems involved during exercise, has been shown to be an important parameter related to morbility and mortality in COPD (Casanova et al., 2007), and is also part of the BODE index (Celli et al., 2004). Although rehabilitation improves both exercise tolerance and quality of life in COPD, it is not known whether these improvements are related to each other. Several trials show the weak correlation between quality of life and the six minute walking distance in patients with COPD suggests that these parameters measure different aspects of health (Wijkstra et al., 1995).

Recently, the use of accelerometer has been incorporated as an objective measure to assess physical activity level of the patient performs daily (Troosters et al., 2010). It is necessary to analyze physical activity in daily life in patients across different disease stages according to GOLD. Other studies have shown that grip strength in the wrist is a strong independent predictor of mortality in COPD (Cortopassi, Divo, Pinto-Plata, \& Celli, 2011). A significant relationship was found between hand grip strength and peripheral muscle strength (flexion of elbow and knee) and strong relationship $(\mathrm{r}=-0.75, \mathrm{p}<0.0001)$ with the force respiratory muscles (maximum inspiratory muscles, inspiratory capacity, forced vital capacity and maximum volume ventilation).

There is no clinical trial review that has found a connection between rehabilitation respiratory programs and an increase in exercise tolerance. It is necessary to clarify the change in quality of life was related with a change in exercise tolerance in COPD patients. The difference between current studies and previous controlled studies (Sinclair, 1980; Vale, Reardon, \& ZuWallack, 1993) are the use of the 12 minute walking distance which is probably more sensitive to change than the six minute walking distance (Wijkstra et al., 1995).

COPD is often associated with exacerbation of symptoms. An exacerbation of COPD is defined as "an event in the natural course for the disease characterized by a change in the patient's baseline dyspnea, cough, and/or sputum that is beyond normal day-to-day variations, is acute in onset, and may warrant a change in regular medication in a patient with underlying COPD" (Burge \& Wedzicha, 2003). The most common causes of an exacerbation are infection of the tracheobronchial tree and air pollution (White, Gompertz, \& Stockley, 2003). Studies investigating effects on pulmonary function and oxigenation did not show benefits in either acute exacerbations of COPD (Newton \& Bevans, 1978) or in chronic COPD (May \& Munt, 1979). Assessment of the severity of an exacerbation is based on the patient's medical history before the exacerbation, pre-existing comorbidities, symptoms, physical examination, arterial blood gas measurements, and other laboratory 
test. Physicians should obtain the results of previous evaluations, where possible, to compare with the current clinical data. Specific information is required on the frequency and severity of attacks of breathlessness and cough, sputum volume and color, and limitation of daily activities (Vilaró et al., 2007).

Other targets of rehabilitation are anxiety control, dyspnea reduction and improvement of the health-related quality of life (Lacasse et al., 2006). The illness evolution can be associated with extra-pulmonary components, such as muscle loss is related with reduction of physical activity. After exacerbation, symptoms of depression have been identified as an independent factor of mortality risk (Yohannes, Baldwin, \& Connolly, 2005), as well as risk a factor for rehabilitation program drop-outs (Garrod, Marshall, Barley, \& Jones, 2006). The skeletal muscle dysfunction and depressive symptoms are potencially amenable to rehabilitation with exercise training (Rodrigues, 2010). We have made the following figure 3 in order to collect intra-pulmonary components (airways obstruction and dyspnea) with extra-pulmonary factors (muscle wasting, reduce mobility, exercise limitation, depression and sedentary lifestyle).

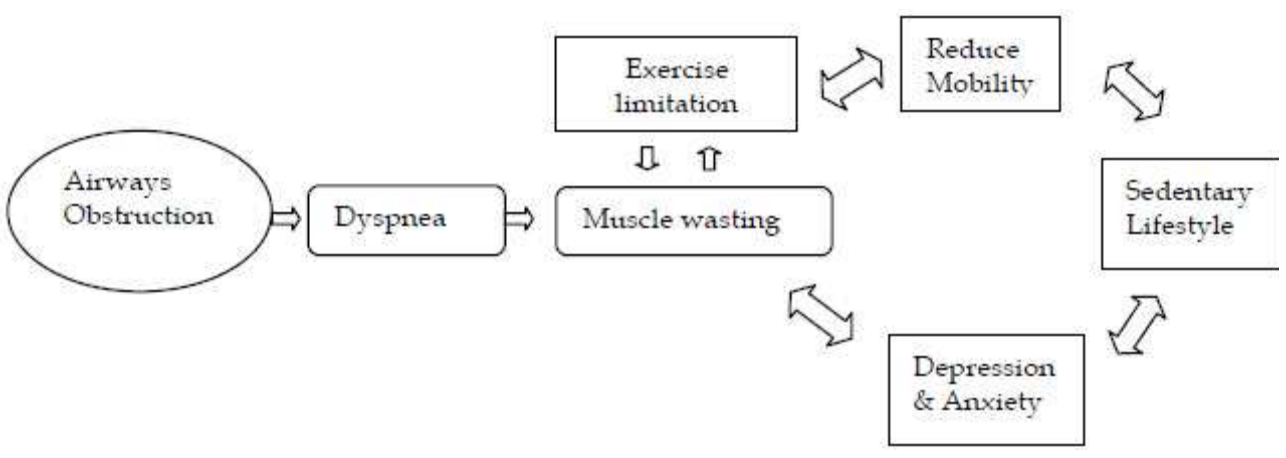

Fig. 3. Relation between intra-pulmonary components with extra-pulmonary factors.

\section{Types of exercises}

Physical activity is defined as any bodily movement produced by skeletal muscles that results in energy expenditure beyond resting energy expenditure (Thompson et al., 2003). Information on the importance of physical activity in COPD has grown, especially in the last few years, although major questions remain to be answered. The present chapter aims to provide an update on the most important studies of physical activity in COPD (Esteban, 2009).

Findings from meta-analysis of pulmonary rehabilitation strongly supports that exercise training as part of treatment of patients with COPD should last at least four weeks (Lacasse, Goldstein, Lasserson, \& Martin, 2006). Exercise training should be available to people with COPD, because it improves breathlessness, quality of life, exercise tolerance and functional ability (Lacasse et al., 2006). Physical therapists are crucial to the delivery of rehabilitation because of their training in exercise and movement therapies (Garrod \& Lasserson, 2007).

The primary goal of the rehabilitation programs is to restore the patient to the highest possible level of independent function (Ries et al., 2007). This goal is accomplished by 
helping patients become more physically active, and to learn more about their disease, treatment options, and how to cope. Within the program of rehabilitation, the physiotherapeutic intervention is responsible for various treatment phases (specifically physical exercise training, peripheral and respiratory muscle training, and breathing exercises) (Langer et al., 2009).

Aerobic exercise is the main non-pharmacological treatment better tolerated by patients with COPD (Martín-Valero, Cuesta-Vargas, \& Labajos-Manzanares, 2010). Exercise training is one of the key components of pulmonary rehabilitation. The exercise prescription for the training program is guided by the following three parameters: intensity; frequency; and duration.

The standarized criterions on intervention period, dose, intensity of physical exercises in COPD patients is needed. Seven (Coppoolse et al., 1999; Kurabayashi et al., 2000; O'Shea, Taylor, \& Paratz, 2004; Puente-Maestu, Sanz, Sanz, Cubillo et al., 2000; Puente-Maestu, Sanz, Sanz, Ruiz de Ona et al., 2000; Wadell, Sundelin, Henriksson-Larsen, \& Lundgren, 2004; Wijkstra et al., 1995) agreed with the criteria of the American College of Sports Medicine (ACSM) (Garber et al., 2011) for the intervention period and number of sessions varied from eight weeks in the majority on trials to twelve weeks in two trials and from two to four sessions a weeks. Therefore, the number sessions a week were at least between two or four sessions a week. Only one trial (Wijkstra et al., 1995) took into account, that patients had to practise twice a day for an individualised protocol, for 0 to 5 hours the first three months and then once a day only for 0-5. The time of sessions is variable in these seven articles with a minimum of 20 minutes up to 60 minutes because two articles do not talk about the time of sessions.

According to the recommendations of the American Association of Cardiovascular and Pulmonary Rehabilitation (AACVPR), high-intensity training targets have been operationally defined to be at least 60 to $80 \%$ of the peak work rate achieved in an incremental maximum exercise test. The intensity of the training sessions in five articles (Coppoolse et al., 1999; Puente-Maestu, Sanz, Sanz, Cubillo et al., 2000; Puente-Maestu, Sanz, Sanz, Ruiz de Ona et al., 2000; Wadell, Sundelin, Henriksson-Larsen, \& Lundgren, 2004; Wijkstra et al., 1995) showed that the goal is $60-90 \%$ of heart rate maximum $\left(\mathrm{HR}_{\max }\right)$ set by the ACSM for improving aerobic fitness ("American college of sports medicine position stand. exercise and physical activity for older adults,"1998a; "American college of sports medicine position stand. The recommended quantity and quality of exercise for developing and maintaining cardiorespiratory and muscular fitness, and flexibility in healthy adults,"1998b)

Exercise training intervention can be adapted to the individual exercise limitations of the patient (Troosters, Gosselink, Langer, \& Decramer, 2007). Troosters et al. review focused on different training types (endurance, interval and resistance training) (Troosters et al., 2007). In this chapter regarding types of exercise training intervention, it has been divided into aerobic and resistance training types. Aerobic exercise training for older people should have a target intensity of $50-85 \%$ of the oxygen uptake reserve - a range that includes both moderate exercise (minimum of 30 minute five days a week) or vigorous exercise (20 minutes three days each week)(Garber et al., 2011).

Resistance training is an ideal intervention for patients with peripheral muscle weakness and pronounced symptoms of dyspnea during exercise (O’Shea, Taylor, \& Paratz, 2004). 
There is not consensus on the optimal method of resistance training (callisthenics, resistance weight training, isometrics or isokinetic-type training) in patients with COPD. Each type produces strength gains highly specific to the type of training. There are no studies that compared different intensities of resistance training in patients with COPD. It is recommended to use (lower limb) resistance training according to ACSM (two or three times a week) ("ACSM", 1998a; "ACSM", 1998b; Garber et al., 2011). Exercises should be performed at $60-80 \%$ of the first repetition maximum (RM), resistance exercises should train 8-10 exercises involving the major muscle groups in bouts of 8-15 repetitions at least 30 minutes a day of moderate-intensity activity on two or three non-consecutive days each week (Nelson et al., 2007). Multiple sets of repetitions (2-5 sets) provide greater benefit (Langer et al., 2009). Resistance activities include a progressive-weight training program, done with therabands (wrist or ankle weights) or progressive weight.

Given that muscle weakness is a common problem in this population, progressive resistance exercise represents a beneficial treatment for improvements in muscle strength (O'Shea, Taylor, \& Paratz, 2009). Moreover, improvements in muscle strength can be obtained when progressive resistance exercise is conducted alone or in combination with aerobic training, indicating that it can be successfully performed in conjunction with other training types during pulmonary rehabilitation (O’Shea, Taylor, \& Paratz, 2009).

Careful consideration is also required when prescribing progressive resistance exercise programs for people with COPD who have comorbid health conditions (O'Shea, Taylor, \& Paratz, 2004). Therefore, progresive resitance exercise may not be appropriate for all people with COPD attending pulmonary rehabilitation, and it is recommended that prescription be targeted to the individual (Storer, 2001).

It is essential to educate the patient about the importance of the training program begining with an initial phase: warming up and stretching (Table 2 Session outline). The central part consists in aerobic training (endurance or interval exercise), resistance training and breathing retraining. Finally, the sessions finish with stretching and relaxation exercises.

\begin{tabular}{|l|l|l|}
\hline \multicolumn{1}{|c|}{ Initial phase } & \multicolumn{1}{|c|}{ Central phase } & \multicolumn{1}{c|}{ Final phase } \\
\hline *Stretching & *Aerobic training & *Stretching \\
*Warming up & (Endurance or Interval) & *Relaxation exercises \\
& * Resistance training & \\
& *Breathing retraining & \\
\hline
\end{tabular}

Table 2. Session outline

It is recommended to apply training strategies that enable patients to resume participation in a rehabilitation programme after an acute exacerbation as soon as possible (Puhan, Scharplatz, Troosters, Walters, \& Steurer, 2009). Resistance training and interval training are best suited for early reactivation of patients. Moreover, arm exercises in patients with COPD were shown to increase arm muscle force (Epstein et al., 1997) and reduce symptoms of dyspnea and fatigue during arm activities (Bauldoff, Hoffman, Sciurba, \& Zullo, 1996).

Patient education is included as an important recommendation in current clinical practice guidelines for COPD (GOLD, 2010; Celli, MacNee, \& ATS/ERS Task Force, 2004) Education should be an integral component of pulmonary rehabilitation (Ries et al., 2007). Moreover, 
education should include information on collaborative self-management and prevention and treatment of exacerbation. So, patient education interventions are necessary to ensure long-term maintenance of treatment effects. Studies with successful results in chronically ill adults both used physical activity self-monitoring (pedometers or diaries) and applied behavioural strategies to increase patient's self efficacy and self-regulatory skills (Conn, Hafdahl, Brown, \& Brown, 2008). It is necessary to initiate and maintain physical activity behaviour change during and after supervised physical exercise training programs. Rose et al., (Baraniak \& Sheffield, 2011; Rose et al., 2002) evaluated psychosocial interventions to treat anxiety and panic in patients with COPD; however the data indicated that there were no changes in cognitive function. Overall, the educational intervention may have facilitated aspects of program adherence.

\subsection{Continuous or incremental aerobic exercise}

In this section different types of physical exercise training that can be applied to improve exercise performance in patients with COPD are presented. The authors have compared programmes with constant load training and incremental load training in COPD patients. There is high level evidence that aerobic training is effective for aerobic capacity and there is moderate evidence that interval training is effective for strength, endurance, functionality and psychosocial parameters (Normandin et al., 2002).

\section{Endurance or continuous training}

Supervised continuous training is recommended for patients in all stages of the disease who are able to perform continuous training of at least moderate intensity. Training frequency should be three times weekly in the first weeks of the exercise programme (Langer et al., 2009). Patients with severe symptoms of dyspnea during exercise are frequently not capable of performing high-intensity (70 to $80 \%$ of the peak work rate) continuous type training (Casaburi et al., 1997; Maltais et al., 1997). It seems that moderate intensity continuous training (50 to $60 \%$ of the peak work rate or 5-6 out of 10 according to the modified Borg Scale) is minimally required to achieve changes in physical fitness. Improvements in healthrelated quality of life after training at moderate intensities were comparable with those observed after high intensity training (Puente-Maestu, Sanz, Sanz, Cubillo et al., 2000).

Lower extremity exercise training at higher exercise intensity produces greater physiologic benefits than lower intensity training in patients with COPD. Moreover, both low-intensity and high-intensity exercise training produce clinical benefits for patients with COPD (Ries, 2008).

Two categories of tasks can be found during everyday activities, endurance and strength tasks. Endurance tasks require repetitive actions over an extended period of time (walking, cycling and swimming) as shown in figure 4 . While strength tasks require explosive performance over short time periods (jumping, lifting weights, sprinting)(Ries et al., 2007). The addition of a strength-training component to a program of pulmonary rehabilitation increases muscle strength and muscle mass (Ries, 2008).

\section{Interval training}

Interval training is recommended as an alternative to continuous training in patients with severe symptoms of dyspnea due to the fact that they are unable to sustain continuous 


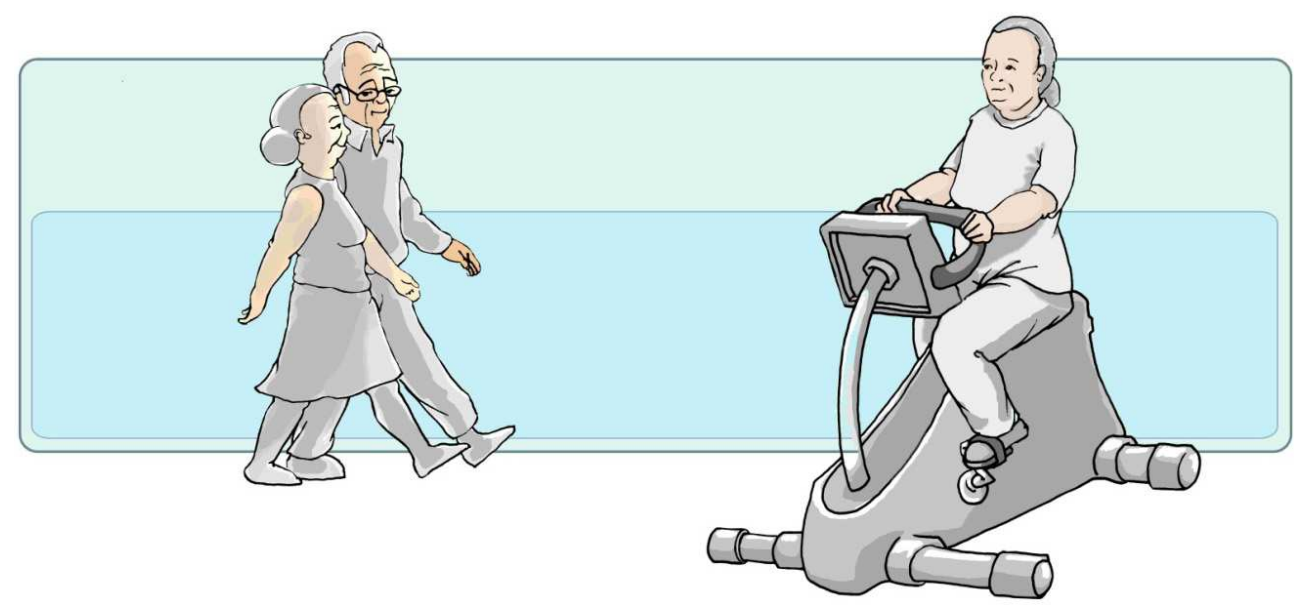

Fig. 4. Endurance tasks taken from “Manual de Rehabilitación Respiratoria para personas con EPOC".

training at the recommended intensities. Short high intensity (at least $70-80 \%$ of peak work rate) exercise bouts of 30-180 seconds are necessary during interval training. Recommended frequency of training is the same as with continuous training (Langer et al., 2009).

Only one article (Puente-Maestu, Sanz, Sanz, Cubillo et al., 2000) showed that patients responded to supervised training with incremented loads also changed their ventilatory pattern to deeper, slower breathing. Therefore, improved ventilation this type of incremental training also tended to be more efficient with an average decrease in dead space. Perhaps, the quality of life questionnaires are not sensitive tools to detect changes in the functional variables of disease progression. The changes produced by aerobic physical training in COPD do not have clinical relevance, but they are a success because it slows down disease progression.

Most patients with severe COPD are not able to sustain a continuous exercise protocol. For these patients, interval exercise represents an alternative because it offers the same benefit as high-intensity exercise. Besides, incremental exercise is better tolerated, as expressed by fewer breaks during the rehabilitation program and better adherence to exercise protocols (Puhan MA et al., 2006). Therapeutic intervention can be done in or out of water; the next section explains the therapeutic aquatic exercise intervention.

\subsection{Therapeutic aquatic exercise intervention}

This intervention is known for its power of prevention and treatment in different conditions, although not considered part of standard pulmonary rehabilitation. Therapeutic aquatic exercise intervention is a discipline that includes hydrotherapy, spa therapy, balneotherapy and physiotherapy, and is used for the prevention and treatment of diseases through water (Geytenbeek, 2008). Hydrotherapy is defined as a complementary therapy that uses the temperature and pressure of water as a therapeutic agent at a given temperature (Geytenbeek, 2002). 
There is controversy in the scientific literature regarding the beneficial and harmful effects of water exercise for the respiratory system in people with respiratory problems. Different types of exercises can be carried out: walking, cycling, lifting weights in a swimming pool (figure 5), and so on. Previous studies show that hydrostatic pressure exerts on inspiratory muscle strength and limited chest expansion; this effect is enhanced as the temperature of the pool water decreases (Frontera, Herring, Micheli, \& Silver, 2008). In addition, the diaphragm moves during diving due to compression by the abdomen, thus decreasing respiratory vital capacity (Greenleaf, 1984). Patients with chronic obstructive pulmonary disease benefit from the hydrostatic pressure exerted during immersion, which facilitates expiration and reduces the residual volume, decreasing the air trapped in this pathology (Asanuma, 1999; Dahlback, 1975; Schoenhofer, Koehler, \& Polkey, 2004). Previous studies show that water exerts hydrostatic pressure on inspiratory muscle strength and limited chest expansion, this effect is enhanced with decreasing the temperature of the pool water (Agostoni, Gurtner, Torri, \& Rahn, 1966). Therapeutic aquatic exercise intervention is known for its ability to prevent and treat different conditions. This intervention is a specialized field of physical training and therapy, used to achieve certain physical and functional goals using the properties of water (Geytenbeek, 2008).

The reviewed articles covered incremental therapeutic aquatic exercise with an intensity ranging from $50 \%$ to $90 \%$ of maximal oxygen consumption $\left(\mathrm{VO}_{2 \max }\right)$ with sessions of 30 to 50 minutes 2 to 5 days a week, for a total of 8 to 24 weeks at a temperature of $29{ }^{\circ} \mathrm{C}$ to $38{ }^{\circ} \mathrm{C}$ (Kurabayashi et al., 2000; Wadell, Sundelin, Henriksson-Larsen, Lundgren, 2004). COPD patients walked in water to the level of their shoulders, and they breathed out slowly through their mouth into water after sinking their nose $3-5 \mathrm{~cm}$ below the water level. The patients` eyes were not under the water. After exercise, patients dressed and rested on a chair in a comfortable room $\left(25^{\circ} \mathrm{C}\right)$ for 30 minutes. Two studies showed clinical changes in the questionnaire of quality of life for respiratory patients. People who performed incremental exercise in the water showed functional changes in the distance walked in the walking test, in forced vital capacity and forced expiratory volume (Kurabayashi et al., 2000; Wadell, Sundelin, Henriksson-Larsen, \& Lundgren, 2004). The aquatic intervention group that performed incremental exercise had improved health-related quality of life, compared to a control group without intervention (Wadell, Sundelin, Henriksson-Larsen, \& Lundgren, 2004).

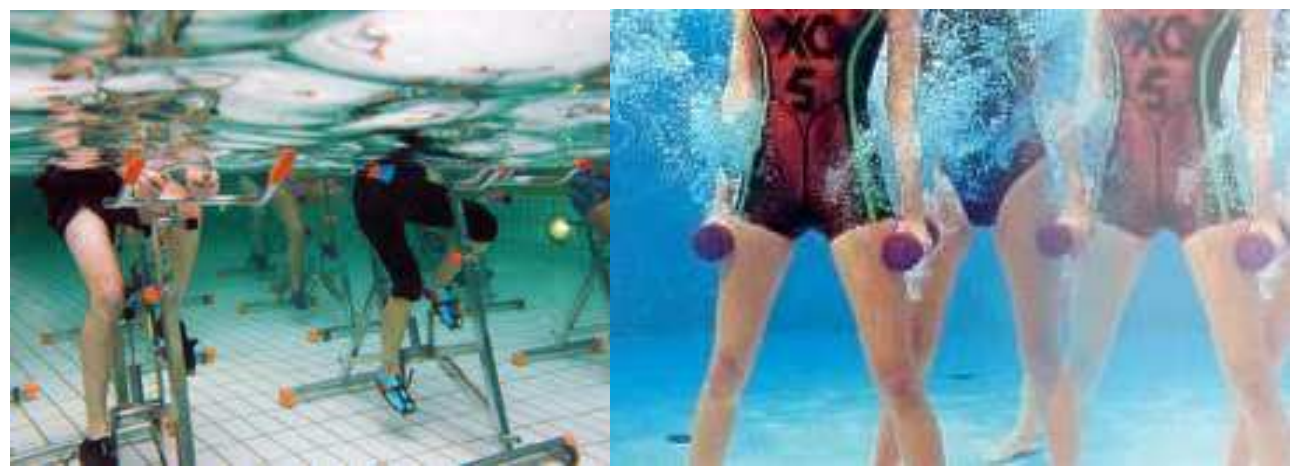

Fig. 5. Cycling and lifting weights 
Physical therapy for COPD requires a certain duration and frequency in order to improve clinical parameters. Wadell et al. (2005a) indicated that training once a week (high intensity/low frequency) was not sufficient to sustain the improvements in physical capacity and quality of life achieved after a period of 3 months of high frequency aquatic exercise training with three sessions of 45 minutes each a week (high intensity/high frequency). However, high intensity physical training once a week for 6 months seemed to be enough to avoid deterioration compared to baseline. According to Kurabayashi's study, 6 consecutive days of exercise a week would be preferable to 3 alternative days of exercise a week, even if the cumulative exercise period was the same (Kurabayashi et al., 1998). The studies reviewed showed much heterogeneity with respect to the duration of treatment, ranging from 6 to 24 weeks. However, the typical duration of treatment was 8 to 12 weeks. Further studies should direct more attention to the specific duration, frequency and accuracy of aerobic intensity thresholds. Other authors found that exercise in water tends to provide even greater benefits than similar exercise training on land (Wadell, Sundelin, Henriksson-Larsen, \& Lundgren, 2004).

Breathing exercises during immersion in water at $38{ }^{\circ} \mathrm{C}$ could be recommended as physical therapy after diagnosis of COPD. Elevation of the sub-peritoneal diaphragmatic pressure by the hydraulic pressure could help raise the diaphragm and assist in the evacuation of air during exhalation, resulting in a decrease in dead space. In addition, hydraulic pressure was reported to increase cardiac output, resulting in an improvement in blood gas exchange in lung capillaries. Besides these effects, inhalation of gas containing thermal hydrogen sulfate lowers the viscosity of sputum (Asanuma, Fujita, Ide, \& Agishi, 1971). Only three studies (Kurabayashi et al., 2000; Kurabayashi et al., 1998; Perk, Perk, \& Bodén, 1996) included breathing exercises during therapeutic aquatic exercise intervention.

\subsection{Respiratory muscle training}

In general, patients with COPD have weak inspiratory muscles (Polkey et al., 1996). This weakness may contribute to dyspnea and exercise limitation in patients with significant COPD. When evaluating the strength of respiratory muscles we should be aware that we are focusing primarily on the ability of these muscles to generate tension during a forced inspiratory or expiratory maneuver. The result of the maneuver can be measured with the mouth (Figure 6 Equipment to maneuver), and it is measured in centimeters $\mathrm{H}_{2} \mathrm{O}$. This primarily reflects a set of variables such as muscle mass (ability to generate force) and length-tension relationship.

The role of inspiratory muscle training (IMT) for individuals with stable COPD is unclear (Geddes, O'Brien, Reid, Brooks, \& Crowe, 2008). The first systematic review on IMT found little evidence to support the use of IMT (Shoemaker, Donker, \& Lapoe, 2009). The Amercian Thoracic Society/European Respiratory Society standards (Celli, MacNee et al., 2004) nor the Canadian Thoracic Society Recommendations for the Management of COPD (O'Donnell et al., 2008) recommend the incorporation of IMT into management plan. The Global Initiative for Chronic Obstructive Lung Disease (GOLD, 2010) states that "respiratory muscle training is beneficial, especially when combined with general exercise training" based on non-randomized trials and observational studies. 


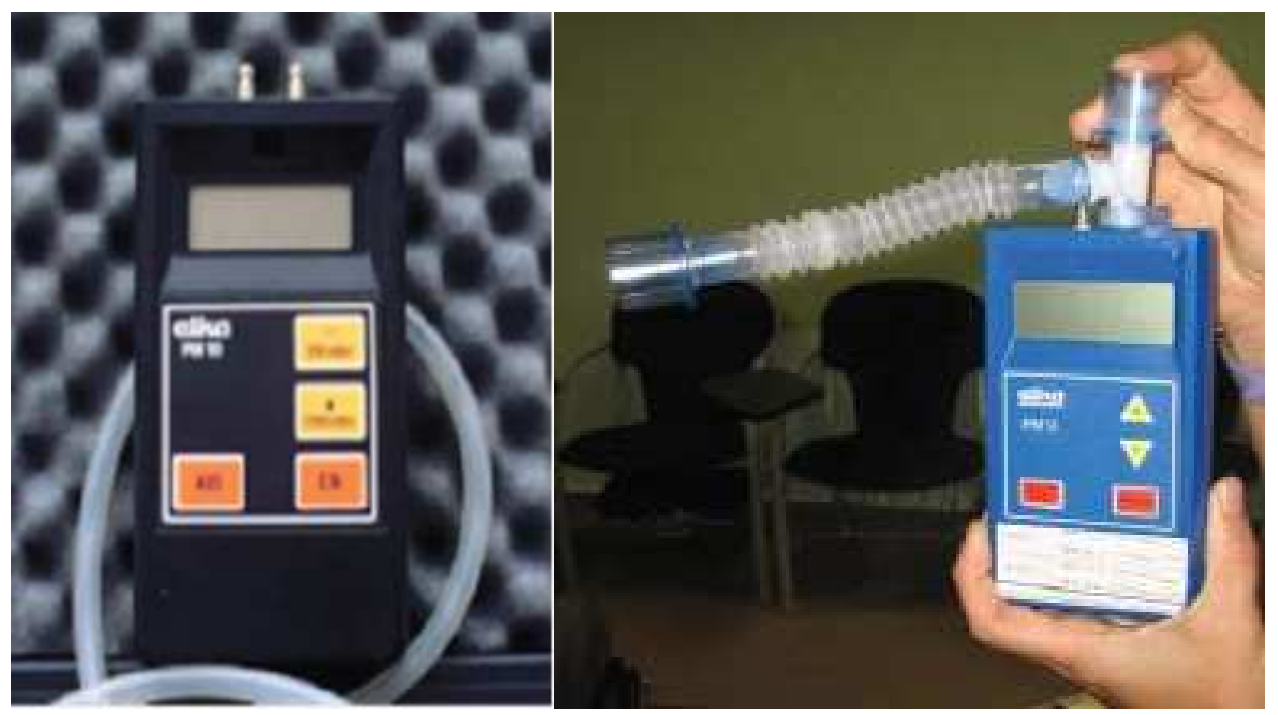

Fig. 6. Equipment to maneuver

In an attempt to reduce the severity of breathlessness and to improve exercise tolerance, IMT has been applied in many COPD patients (Weiner, Magadle, Beckerman, Weiner, \& Berar-Yanay, 2003). Several different respiratory muscle training devices are available, ranging from sophisticated computerized systems to simple hand-held resistive devices. In addition, the relative benefits of strength versus endurance training, inspiratory versus expiratory training and effect in patients of differing severity are unknown (Garrod \& Lasserson, 2007)

Types of intervention: Sham, low- and high-intensity IMT

There are studies comparing the effect of different types of intervention (Geddes, Reid, Crowe, O'Brien, \& Brooks, 2005). In order to standardize studies that showed sham IMT and low intensity IMT at similar percentages of maximum inspiratory pression (PImax). Bégin et al., (Begin \& Grassino, 1991) measured these loads using the tidal inspiratory pressure (PI) of individuals with COPD. Sham IMT was defined as that using the same type of device as the intervention group at an intensity less than or equal to the mean plus one standard deviation (SD). Since PI is directly proportional to the partial pressure of carbon dioxide in the arterial blood $\left(\mathrm{PCO}_{2}\right)$ of patients with COPD (Begin \& Grassino, 1991), sham IMT for normocapneic individuals was defined as intensity p8.3 $\mathrm{cm} \mathrm{H}_{2} \mathrm{O}$ (mean PI +1 SD) and for individuals with moderate hypercapnia, as intensity p11.5 $\mathrm{cm} \mathrm{H}_{2} \mathrm{O}$ (Geddes et al., 2005).

Using IMT in combination with other interventions and using flow-dependent resistive training is important in the pulmonary rehabilitation program (Geddes et al., 2008). However, there are no established thresholds for what constitutes a clinically meaningful change in inspiratory muscle strength or endurance, other methods must be utilized to infer clinical benefit (Shoemaker et al., 2009). Geddes et al. (2005) recommended using IMT at least a total of 30 minutes daily but can be spread over more than one session a day. Training should occur at least 5 days a week. While gains may be measurable after as short 
as 5 weeks, IMT should become part of the individual's exercise program. The minimal training intensity necessary could start as low as $22 \%$ PImax and be progressed to as high as $60 \%$ PImax using a targeted inspiratory resistive or threshold trainer (Geddes et al., 2005). Therefore, IMT significantly increased inspiratory muscle strength and inspiratory muscle endurance (Lotters, van Tol, Kwakkel, \& Gosselink, 2002). In addition, research review found a clinically significant decrease in dyspnea sensation at rest and during exercise is observed after IMT (Lotters et al., 2002).

In conclusion, IMT improves inspiratory muscle strength and endurance, functional exercise capacity, dyspnea and quality of life. Inspiratory muscle endurance training was shown to be less effective than respiratory muscle strength training. In patients with inspiratory muscle weakness, the addition of IMT to a general exercise training program improved PImax and tended to improve exercise performance (Gosselink et al., 2011).

Furthermore, maximal inspiratory pressure is a volitional test and therefore open to criticism (Polkey \& Moxham, 2004). Futher research is needed to explore the impact that different training protocols (frequency, intensity and duration of IMT, supervision) may have on outcomes and to determine the extent to which changes in outcomes associated with IMT translate into clinically important improvement for adults with COPD (Geddes et al., 2008).

\section{Implications}

In the research reviewed, there are strong arguments that pulmonary rehabilitation is beneficial for improving the quality of life related to health at the beginning of the program. Furthermore pulmonary rehabilitation reduces symptoms and increases participation in everyday activities. However, it is necessary to do more randomized controlled trials to clarify which components of the lung rehabilitation are essential. Future studies to discover the ideal length of treatment, the necessary degree of supervision, training intensity and how long the treatment effect persists.

Without no doubt, it is necessary to individualize programs for this population taking into account their different levels of severity. The prescription should begin at low intensity and short duration, for both parameters gradually increasing to the threshold of fatigue.

In summary, incremental aerobic resistance physical exercises are better than constant load physical exercises at an intensity range from $90 \%$ to $50 \%$ of $\mathrm{VO}_{2}$ max, with a frequency of two or four days a week, the session is from 30 to 60 minutes during a period of treatment from eight to twelve weeks. Exercise training induces several symptomatic and functional adaptations resulting in an increased aerobic capacity, although clinical relevance is not collected in the study population. Maybe, for further studies we should take intrinsic patient factor (severity of COPD) into account over a longer period of time and how extrinsic factors of the exercises affect disease progression. Moreover, it is important to determine whether these physiological benefits of COPD patients who have performed an incremental aerobic resistance physical exercises program supervised justify the increased costs. Therefore, a cost/effectiveness analysis is necessary to determining whether the type of intervention program is supervised or not.

It is essential to investigate physical activity in daily life in patients with COPD in accordance to the GOLD stages. Pulmonary rehabilitation programs should incorporate the 
use of an accelerometer, the values of respiratory muscle strength and peripheral muscle strength (hand grip, knee- extension); also more sensitive tools for detecting changes in exercise tolerance should be included.

\section{References}

Agostoni, E., Gurtner, G., Torri, G., \& Rahn, H. (1966). Respiratory mechanics during submersion and negative-pressure breathing. Journal of Applied Physiology, 21(1), 251-258.

American college of sports medicine position stand exercise and physical activity for older adults. (1998a). Medicine and Science in Sports and Exercise, 30(6), 992-1008.

American college of sports medicine position stand. The recommended quantity and quality of exercise for developing and maintaining cardiorespiratory and muscular fitness, and flexibility in healthy adults.(1998b). Medicine and Science in Sports and Exercise, 30(6), 975-991.

American Thoracic Society, \& American College of Chest Physicians. (2003). ATS/ACCP statement on cardiopulmonary exercise testing. American Journal of Respiratory and Critical Care Medicine, 167(2), 211-277. doi:10.1164/rccm.167.2.211

Ancochea Bermúdez J, et al. (2009). Estrategia en EPOC del sistema nacional de salud Retrieved 2011, from

http://www.msc.es/organizacion/sns/planCalidadSNS/docs/EstrategiaEPOCS NS.pdf

Araujo, Z. T., \& Holanda, G. (2010). Does the BODE index correlate with quality of life in patients with COPD? Jornal Brasileiro De Pneumologia: Publicacao Oficial Da Sociedade Brasileira De Pneumologia e Tisilogia, 36(4), 447-452.

Asanuma Y, Fujita S, Ide H, \& Agishi Y. (1971). Improvement of respiratory resistane by hot water immersing exercise in adult asthmatic patient. Clinical Rehabilitation, 1, 211217.

Asanuma Y. (1999). Influence of water immersion on lung volumes and pulmonary diffusing capacity. A comparison of healthy subjects and patients with chronic obstructive pulmonary disease. Japanese Journal of Clinical Physiology, 29(3), 187-192.

ATS Committee on Proficiency Standards for Clinical Pulmonary Function Laboratories. (2002). ATS statement: Guidelines for the six-minute walk test. American Journal of Respiratory and Critical Care Medicine, 166(1), 111-117.

Baraniak, A., \& Sheffield, D. (2011). The efficacy of psychologically based interventions to improve anxiety, depression and quality of life in COPD: A systematic review and meta-analysis. Patient Education and Counseling, 83(1), 29-36. doi:10.1016/ j.pec.2010.04.010

Barbera, J. A., Peces-Barba, G., Agustí, A. G., Izquierdo, J. L., Monsó, E., Montemayor, T., et al. (2001). Guía clínica para el diagnóstico y el tratamiento de la enfermedad pulmonar obstructiva crónica. Archivos Bronconeumología, 37(6), 297-316.

Bauldoff, G. S., Hoffman, L. A., Sciurba, F., \& Zullo, T. G. (1996). Home-based, upper-arm exercise training for patients with chronic obstructive pulmonary disease. Heart $\mathcal{E}$ Lung : The Journal of Critical Care, 25(4), 288-294.

Bausewein, C., Farquhar, M., Booth, S., Gysels, M., \& Higginson, I. J. (2007). Measurement of breathlessness in advanced disease: A systematic review. Respiratory Medicine, 101(3), 399-410. doi:10.1016/j.rmed.2006.07.003 
Begin, P., \& Grassino, A. (1991). Inspiratory muscle dysfunction and chronic hypercapnia in chronic obstructive pulmonary disease. The American Review of Respiratory Disease, 143(5 Pt 1), 905-912.

Berry, M. J., Rejeski, W. J., Adair, N. E., Ettinger, W. H.,Jr, Zaccaro, D. J., \& Sevick, M. A. (2003). A randomized, controlled trial comparing long-term and short-term exercise in patients with chronic obstructive pulmonary disease. Journal of Cardiopulmonary Rehabilitation, 23(1), 60-68.

Borg, E., Borg, G., Larsson, K., Letzter, M., \& Sundblad, B. M. (2010). An index for breathlessness and leg fatigue. Scandinavian Journal of Medicine $\mathcal{E}$ Science in Sports, 20(4), 644-650. doi:10.1111/j.1600-0838.2009.00985.x

Brooks, D., Solway, S., \& Gibbons, W. J. (2003). ATS statement on six-minute walk test. American Journal of Respiratory and Critical Care Medicine, 167(9), 1287.

Burge, S., \& Wedzicha, J. A. (2003). COPD exacerbations: Definitions and classifications. The European Respiratory Journal.Supplement, 41, 46s-53s.

Camargo, L. A., \& Pereira, C. A. (2010). Dyspnea in COPD: Beyond the modified medical research council scale. Jornal Brasileiro De Pneumologia: Publicacao Oficial Da Sociedade Brasileira De Pneumologia e Tisilogia, 36(5), 571-578.

Casaburi, R., Porszasz, J., Burns, M. R., Carithers, E. R., Chang, R. S., \& Cooper, C. B. (1997). Physiologic benefits of exercise training in rehabilitation of patients with severe chronic obstructive pulmonary disease. American Journal of Respiratory and Critical Care Medicine, 155(5), 1541-1551.

Casanova, C., Cote, C. G., Marin, J. M., de Torres, J. P., Aguirre-Jaime, A., Mendez, R., et al. (2007). The 6-min walking distance: Long-term follow up in patients with COPD. The European Respiratory Journal: Official Journal of the European Society for Clinical Respiratory Physiology, 29(3), 535-540. doi:10.1183/09031936.00071506

Celli, B. R., Cote, C. G., Marin, J. M., Casanova, C., Montes de Oca, M., Mendez, R. A., et al. (2004). the body-mass index, airflow obstruction, dyspnea, and exercise capacity index in chronic obstructive pulmonary disease. The New England Journal of Medicine, 350(10), 1005-1012. doi:10.1056/NEJMoa021322

Celli, B. R., MacNee, W., \& ATS/ERS Task Force. (2004). Standards for the diagnosis and treatment of patients with COPD: A summary of the ATS/ERS position paper. The European Respiratory Journal : Official Journal of the European Society for Clinical Respiratory Physiology, 23(6), 932-946.

Clini, E., Foglio, K., Bianchi, L., Porta, R., Vitacca, M., \& Ambrosino, N. (2001). In-hospital short-term training program for patients with chronic airway obstruction. Chest, 120(5), 1500-1505.

Conn, V. S., Hafdahl, A. R., Brown, S. A., \& Brown, L. M. (2008). Meta-analysis of patient education interventions to increase physical activity among chronically ill adults. Patient Education and Counseling, 70(2), 157-172. doi:10.1016/j.pec.2007.10.004

Coppoolse, R., Schols, A. M., Baarends, E. M., Mostert, R., Akkermans, M. A., Janssen, P. P., et al. (1999). Interval versus continuous training in patients with severe COPD: A randomized clinical trial. The European Respiratory Journal : Official Journal of the European Society for Clinical Respiratory Physiology, 14(2), 258-263.

Cortopassi, F., Divo, M., Pinto-Plata, V., \& Celli, B. (2011). Resting handgrip force and impaired cardiac function at rest and during exercise in COPD patients. Respiratory Medicine, In Press, Corrected Proof doi:DOI: 10.1016/j.rmed.2010.12.011 
Couillard A, \& Prefaut C. (2005). From muscle disuse to myopathy in COPD: Potencial contribution of oxidative stress. European Respiratory journal, 26(4), 703-719.

Dahlback, G. O. (1975). Influence of intrathoracic blood pooling on pulmonary air-trapping during immersion. Undersea Biomedical Research, 2(2), 133-140.

Eaton, T., Young, P., Nicol, K., \& Kolbe, J. (2006). The endurance shuttle walking test: A responsive measure in pulmonary rehabilitation for COPD patients. Chronic Respiratory Disease, 3(1), 3-9.

Epstein, S. K., Celli, B. R., Martinez, F. J., Couser, J. I., Roa, J., Pollock, M., et al. (1997). Arm training reduces the VO2 and VE cost of unsupported arm exercise and elevation in chronic obstructive pulmonary disease. Journal of Cardiopulmonary Rehabilitation, 17(3), 171-177.

Esteban, C. (2009). Role of physical activity in chronic obstructive pulmonary disease. [Impacto de la actividad física en la EPOC] Archivos de Bronconeumología, 45 Suppl 5, 7-13. doi:10.1016/S0300-2896(09)72949-7

Esteban, C., Quintana, J. M., Aburto, M., Moraza, J., Egurrola, M., Perez-Izquierdo, J., et al. (2010). Impact of changes in physical activity on health-related quality of life among patients with COPD. The European Respiratory Journal : Official Journal of the European Society for Clinical Respiratory Physiology, 36(2), 292-300. doi:10.1183/ 09031936.00021409

Fishman, A. P. (2008). Pulmonary diseases and disorders (4th ed.). New York: McGraw-Hill.

Foy, C. G., Rejeski, W. J., Berry, M. J., Zaccaro, D., \& Woodard, C. M. (2001). Gender moderates the effects of exercise therapy on health-related quality of life among COPD patients. Chest, 119(1), 70-76.

Frontera W.R., Herring S.A., Micheli L.J., \& Silver J.K. (2008). Medicina deportiva clínica: tratamiento médico y rehabilitación Elsevier.

Garber, C. E., Blissmer, B., Deschenes, M. R., Franklin, B. A., Lamonte, M. J., Lee, I. M., et al. (2011). Quantity and quality of exercise for developing and maintaining cardiorespiratory, musculoskeletal, and neuromotor fitness in apparently healthy adults: Guidance for prescribing exercise. Medicine and Science in Sports and Exercise, 43(7), 1334-1359. doi:10.1249/MSS.0b013e318213fefb

Garrod, R., Marshall, J., Barley, E., \& Jones, P. W. (2006). Predictors of success and failure in pulmonary rehabilitation. The European Respiratory Journal : Official Journal of the European Society for Clinical Respiratory Physiology, 27(4), 788-794. doi:10.1183/ 09031936.06.00130605

Garrod, R., \& Lasserson, T. (2007). Role of physiotherapy in the management of chronic lung diseases: An overview of systematic reviews. Respiratory Medicine, 101(12), 24292436. doi:10.1016/j.rmed.2007.06.007

Geddes, E. L., Reid, W. D., Crowe, J., O'Brien, K., \& Brooks, D. (2005). Inspiratory muscle training in adults with chronic obstructive pulmonary disease: A systematic review. Respiratory Medicine, 99(11), 1440-1458. doi:10.1016/j.rmed.2005.03.006

Geddes, E. L., O'Brien, K., Reid, W. D., Brooks, D., \& Crowe, J. (2008). Inspiratory muscle training in adults with chronic obstructive pulmonary disease: An update of a systematic review. Respiratory Medicine, 102(12), 1715-1729. doi:10.1016/ j.rmed.2008.07.005

Geytenbeek, J. (2002). Evidence for effective hydrotherapy. Physiotherapy, 88(9), 514-529. doi:DOI: 10.1016/S0031-9406(05)60134-4 
Geytenbeek J. (2008). Aquatic physiotherapy evidence-based practice guide. Retrieved from http:/ / www.npz-nrz.nl/downloads/files/Plenair\%20Marijke\%20HopmanRock2.pdf Global iniciative for chronic obstructive lung disease (GOLD). (2010). Retrieved Marzo/23, 2011, from http://www.goldcopd.com

Gosselink, R., De Vos, J., van den Heuvel, S. P., Segers, J., Decramer, M., \& Kwakkel, G. (2011). Impact of inspiratory muscle training in patients with COPD: What is the evidence? The European Respiratory Journal : Official Journal of the European Society for Clinical Respiratory Physiology, 37(2), 416-425. doi:10.1183/09031936.00031810

Green, R. H., Singh, S. J., Williams, J., \& Morgan, M. D. (2001). A randomised controlled trial of four weeks versus seven weeks of pulmonary rehabilitation in chronic obstructive pulmonary disease. Thorax, 56(2), 143-145.

Greenleaf J E. (1984). Physiological responses to prolonged bed rest and fluid immersion in humans. Journal of Applied Physiology, 57(3), 619-633.

Gruffydd-Jones, K., \& Loveridge, C. (2011). The 2010 NICE COPD guidelines: How do they compare with the GOLD guidelines? Primary Care Respiratory Journal: Journal of the General Practice Airways Group, 20(2), 199-204. doi:10.4104/pcrj.2011.00011

Guyatt, G. H., Berman, L. B., Townsend, M., Pugsley, S. O., \& Chambers, L. W. (1987). A measure of quality of life for clinical trials in chronic lung disease. Thorax, 42(10), 773-778.

Hilberink, S. R., Jacobs, J. E., van Opstal, S., van der Weijden, T., Keegstra, J., Kempers, P. L., et al. (2011). Validation of smoking cessation self-reported by patients with chronic obstructive pulmonary disease. International Journal of General Medicine, 4, 85-90. doi:10.2147/IJGM.S15231

Jones, P. W., Quirk, F. H., Baveystock, C. M., \& Littlejohns, P. (1992). A self-complete measure of health status for chronic airflow limitation. the st. george's respiratory questionnaire. The American Review of Respiratory Disease, 145(6), 1321-1327.

Jones, P. W. (2001). Health status measurement in chronic obstructive pulmonary disease. Thorax, 56(11), 880-887.

Jones PW. (2002). Interpreting thresholds for a clinically significant change in health status in asthma and COPD. Eur Respir j., 19, 398-404. doi:10.1183/09031936.02.00063702

Kurabayashi H, Machida I, Tamura K, Iwai F, Tamura J, \& Kubota K. (2000). Breathing out into water during subtotal immersion: A therapy for chronic pulmonary emphysema. American Journal of Physical Medicine E Rehabilitation, 79, 150-153.

Kurabayashi, H., Machida, I., Hnda H., Akiba T., Kubota K., et al. (1998). Comparison of three protocols for breathing exercises during immersion in $38^{\circ} \mathrm{C}$ water for chronic obstructive pulmonary disease. American Journal of Physical Medicine $\mathcal{E}$ Rehabilitation, 77(2), 145-147.

Lacasse, Y., Goldstein, R., Lasserson, T. J., \& Martin, S. (2006). Pulmonary rehabilitation for chronic obstructive pulmonary disease. Cochrane Database of Systematic Reviews (Online), (4)(4), CD003793. doi:10.1002/14651858.CD003793.pub2

Langer, D., Hendriks, E., Burtin, C., Probst, V., van der Schans, C., Paterson, W., et al. (2009). A clinical practice guideline for physiotherapists treating patients with chronic obstructive pulmonary disease based on a systematic review of available evidence. Clinical Rehabilitation, 23(5), 445-462. doi:10.1177/0269215509103507

Laszlo, G. (2006). Standardisation of lung function testing: Helpful guidance from the ATS/ERS task force. Thorax, 61(9), 744-746. doi:10.1136/thx.2006.061648 
Lotters, F., van Tol, B., Kwakkel, G., \& Gosselink, R. (2002). Effects of controlled inspiratory muscle training in patients with COPD: A meta-analysis. The European Respiratory Journal: Official Journal of the European Society for Clinical Respiratory Physiology, 20(3), 570-576.

Mahler, D. A., Mejia-Alfaro, R., Ward, J., \& Baird, J. C. (2001). Continuous measurement of breathlessness during exercise: Validity, reliability, and responsiveness. Journal of Applied Physiology (Bethesda, Md.: 1985), 90(6), 2188-2196.

Mahler, D. A. (2006). Mechanisms and measurement of dyspnea in chronic obstructive pulmonary disease. Proceedings of the American Thoracic Society, 3(3), 234-238. doi:10.1513/pats.200509-103SF

Manual para la rehabilitación respiratoria para personas con EPOC. Retrieved from Manual_de_Rehabilitacion_Respiratoria_para_personas_con_EPOC.pdf

Maltais, F., LeBlanc, P., Jobin, J., Berube, C., Bruneau, J., Carrier, L., et al. (1997). Intensity of training and physiologic adaptation in patients with chronic obstructive pulmonary disease. American Journal of Respiratory and Critical Care Medicine, 155(2), 555-561.

Martín-Valero R, Cuesta-Vargas AI, \& Labajos-Manzanares MT. (2010). Revisión de ensayos clínicos sobre rehabilitación respiratoria en enfermos pulmonares obstructivos crónicos. Rehabilitación, 44(2), 158-66.

May, D. B., \& Munt, P. W. (1979). Physiologic effects of chest percussion and postural drainage in patients with stable chronic bronchitis. Chest, 75(1), 29-32.

National Clinical Guideline Centre. (2010) Chronic obstructive pulmonary disease: management of chronic obstructive pulmonary disease in adults in primary and secondary care. London: National Clinical Guideline Centre. Available from: http://guidance.nice.org.uk/CG101/Guidance/pdf/English

Miller, M. R., Hankinson, J., Brusasco, V., Burgos, F., Casaburi, R., Coates, A., et al. (2005). Standardisation of spirometry. The European Respiratory Journal: Official Journal of the European Society for Clinical Respiratory Physiology, 26(2), 319-338. doi:10.1183/ 09031936.05.00034805

Nelson, M. E., Rejeski, W. J., Blair, S. N., Duncan, P. W., Judge, J. O., King, A. C., et al. (2007). Physical activity and public health in older adults: Recommendation from the american college of sports medicine and the american heart association. Circulation, 116(9), 1094-1105. doi:10.1161/CIRCULATIONAHA.107.185650

Newton, D. A., \& Bevans, H. G. (1978). Physiotherapy and intermittent positive-pressure ventilation of chronic bronchitis. British Medical Journal, 2(6151), 1525-1528.

Nici, L., Donner, C., Wouters, E., Zuwallack, R., Ambrosino, N., Bourbeau, J., et al. (2006). American thoracic Society/European respiratory society statement on pulmonary rehabilitation. American Journal of Respiratory and Critical Care Medicine, 173(12), 1390-1413. doi:10.1164/rccm.200508-1211ST

Normandin, E. A., McCusker, C., Connors, M., Vale, F., Gerardi, D., \& ZuWallack, R. L. (2002). An evaluation of two approaches to exercise conditioning in pulmonary rehabilitation. Chest, 121(4), 1085-1091.

O'Donnell, D. E., Hernandez, P., Kaplan, A., Aaron, S., Bourbeau, J., Marciniuk, D., et al. (2008). Canadian thoracic society recommendations for management of chronic obstructive pulmonary disease - 2008 update - highlights for primary care. Canadian Respiratory Journal : Journal of the Canadian Thoracic Society, 15 Suppl A, 1A-8A. 
Okubadejo, A. A., Jones, P. W., \& Wedzicha, J. A. (1996). Quality of life in patients with chronic obstructive pulmonary disease and severe hypoxaemia. Thorax, 51(1), 44-47.

O'Shea, S. D., Taylor, N. F., \& Paratz, J. (2004). Peripheral muscle strength training in COPD: A systematic review. Chest, 126(3), 903-914. doi:10.1378/chest.126.3.903

O'Shea, S. D., Taylor, N. F., \& Paratz, J. (2009). Progressive resistance exercise improves muscle strength and may improve elements of performance of daily activities for people with COPD: A systematic review. Chest, 136, 1269-1283. Doi 10.1378/chest.09-0029

Pepin, V., Saey, D., Whittom, F., LeBlanc, P., \& Maltais, F. (2005). Walking versus cycling: Sensitivity to bronchodilation in chronic obstructive pulmonary disease. American Journal of Respiratory and Critical Care Medicine, 172(12), 1517-1522. doi:10.1164/rccm.200507-1037OC

Pepin, V., Brodeur, J., Lacasse, Y., Milot, J., Leblanc, P., Whittom, F., et al. (2007). Six-minute walking versus shuttle walking: Responsiveness to bronchodilation in chronic obstructive pulmonary disease. Thorax, 62(4), 291-298. doi:10.1136/thx.2006.065540

Perk J, Perk L, \& Bodén C. (1996). Cardiorespiratory adaptation of COPD patients to physical training on land and in water. European Respiratory Journal, 9(2), 248-252.

Polkey, M. I., Kyroussis, D., Hamnegard, C. H., Mills, G. H., Green, M., \& Moxham, J. (1996). Diaphragm strength in chronic obstructive pulmonary disease. American Journal of Respiratory and Critical Care Medicine, 154(5), 1310-1317.

Polkey, M. I., \& Moxham, J. (2004). Improvement in volitional tests of muscle function alone may not be adequate evidence that inspiratory muscle training is effective. The European Respiratory Journal : Official Journal of the European Society for Clinical Respiratory Physiology, 23(1), 5-6.

Puente-Maestu, L., Sanz, M. L., Sanz, P., Cubillo, J. M., Mayol, J., \& Casaburi, R. (2000). Comparison of effects of supervised versus self-monitored training programmes in patients with chronic obstructive pulmonary disease. The European Respiratory Journal: Official Journal of the European Society for Clinical Respiratory Physiology, 15(3), 517-525.

Puente-Maestu, L., Sanz, M. L., Sanz, P., Ruiz de Ona, J. M., Rodriguez-Hermosa, J. L., \& Whipp, B. J. (2000). Effects of two types of training on pulmonary and cardiac responses to moderate exercise in patients with COPD. The European Respiratory Journal: Official Journal of the European Society for Clinical Respiratory Physiology, 15(6), 1026-1032.

Puhan MA, Büsching G, Chünemann HJ, vanOort E, Zaugg C, \& Frey M. (2006). Interval versus continuous high-intensity exercise in chronic obstructive pulmonary disease. A randomized trial. Annals of Internal Medicine, 145, 816-825.

Puhan, M., Scharplatz, M., Troosters, T., Walters, E. H., \& Steurer, J. (2009). Pulmonary rehabilitation following exacerbations of chronic obstructive pulmonary disease. Cochrane Database of Systematic Reviews (Online), (1)(1), CD005305. doi:10.1002/14651858.CD005305.pub2

Rabe, K. F., Hurd, S., Anzueto, A., Barnes, P. J., Buist, S. A., Calverley, P., et al. (2007). Global strategy for the diagnosis, management, and prevention of chronic obstructive pulmonary disease: GOLD executive summary. American Journal of Respiratory and Critical Care Medicine, 176(6), 532-555. doi:10.1164/rccm.200703-456SO 
Rabinovich, R. A., Ardite, E., Troosters, T., Carbo, N., Alonso, J., Gonzalez de Suso, J. M., et al. (2001). Reduced muscle redox capacity after endurance training in patients with chronic obstructive pulmonary disease. American Journal of Respiratory and Critical Care Medicine, 164(7), 1114-1118.

Rabinovich, R. A., \& Vilaro, J. (2010). Structural and functional changes of peripheral muscles in chronic obstructive pulmonary disease patients. Current Opinion in Pulmonary Medicine, 16(2), 123-133. doi:10.1097/MCP.0b013e328336438d

Ramsey, S. D., \& Sullivan, S. D. (2003). The burden of illness and economic evaluation for COPD. The European Respiratory Journal.Supplement, 41, 29s-35s.

Reda, A. A., Kotz, D., Kocks, J. W., Wesseling, G., \& van Schayck, C. P. (2010). Reliability and validity of the clinical COPD questionniare and chronic respiratory questionnaire. Respiratory Medicine, 104(11), 1675-1682. doi:10.1016/ j.rmed.2010.04.023

Ries, A. L., Bauldoff, G. S., Carlin, B. W., Casaburi, R., Emery, C. F., Mahler, D. A., et al. (2007). Pulmonary rehabilitation: Joint ACCP/AACVPR evidence-based clinical practice guidelines. Chest, 131(5 Suppl), 4S-42S. doi:10.1378/chest.06-2418

Ries, A. L. (2008). Pulmonary rehabilitation: Summary of an evidence-based guideline. Respiratory Care, 53(9), 1203-1207.

Rodrigues, F. (2010). Role of extra-pulmonary factors - depression, muscle weakness, healthrelated quality of life - in COPD evolution. Revista Portuguesa De Pneumologia, 16(5), 709-715.

Rose, C., Wallace, L., Dickson, R., Ayres, J., Lehman, R., Searle, Y., et al. (2002). The most effective psychologically-based treatments to reduce anxiety and panic in patients with chronic obstructive pulmonary disease (COPD): A systematic review. Patient Education and Counseling, 47(4), 311-318.

Schoenhofer, B., Koehler, D., \& Polkey, M. I. (2004). Influence of immersion in water on muscle function and breathing pattern in patients with severe diaphragm weakness. Chest, 125(6), 2069-2074.

Schrier, A. C., Dekker, F. W., Kaptein, A. A., \& Dijkman, J. H. (1990). Quality of life in elderly patients with chronic nonspecific lung disease seen in family practice. Chest, 98(4), 894-899.

Shoemaker, M. J., Donker, S., \& Lapoe, A. (2009). Inspiratory muscle training in patients with chronic obstructive pulmonary disease: The state of the evidence. Cardiopulmonary Physical Therapy Journal, 20(3), 5-15.

Sinclair DJM, I. C. (1980). Controlled trial of supervised exercise training in chronic bronchitis. BMJ, 1, 519-521.

Sobradillo, V., Miravitlles, M., Jiménez, C. A., Gabriel, R., Viejo, J. L., Masa, J. F., et al. (1999). Estudio IBERPOC en españa: Prevalencia de sintomas respiratorios habituales y de limitación crónica al flujo aéreo. Archivos Bronconeumologia, 35(4), 159-166.

Storer, T. W. (2001). Exercise in chronic pulmonary disease: Resistance exercise prescription. Medicine and Science in Sports and Exercise, 33(7 Suppl), S680-92.

Sullivan, S. D., Ramsey, S. D., \& Lee, T. A. (2000). The economic burden of COPD. Chest, 117(2 Suppl), 5S-9S.

Thompson, P. D., Buchner, D., Pina, I. L., Balady, G. J., Williams, M. A., Marcus, B. H., et al. (2003). Exercise and physical activity in the prevention and treatment of atherosclerotic cardiovascular disease: A statement from the council on clinical 
cardiology (subcommittee on exercise, rehabilitation, and prevention) and the council on nutrition, physical activity, and metabolism (subcommittee on physical activity). Circulation, 107(24), 3109-3116. doi:10.1161/01.CIR.0000075572.40158.77

Troosters, T., Gosselink, R., \& Decramer, M. (2000). Short- and long-term effects of outpatient rehabilitation in patients with chronic obstructive pulmonary disease: A randomized trial. The American Journal of Medicine, 109(3), 207-212.

Troosters, T., Gosselink, R., Langer, D., \& Decramer, M. (2007). Pulmonary rehabilitation in chronic obstructive pulmonary disease. Respiratory Medicine: COPD Update, 3(2), 5764. doi:DOI: 10.1016/j.rmedu.2007.02.003

Troosters, T., Sciurba, F., Battaglia, S., Langer, D., Valluri, S. R., Martino, L., et al. (2010). Physical inactivity in patients with COPD, a controlled multi-center pilot-study. Respiratory Medicine, 104(7), 1005-1011. doi:DOI: 10.1016/j.rmed.2010.01.012

Vale F, Reardon JZ, ZuWallack RL. (1993). The long-term benefits of outpatient pulmonary rehabilitation on exercise tolerance and quality of life. Chest, 103, 42-45.

Verrill, D., Barton, C., Beasley, W., \& Lippard, W. M. (2005). The effects of short-term and long-term pulmonary rehabilitation on functional capacity, perceived dyspnea, and quality of life. Chest, 128(2), 673-683. doi:10.1378/chest.128.2.673

Vilaró, J., Gimeno, E., Sánchez Férez, N., Hernando, C., Díaz, I., Ferrer, M., et al. (2007). Actividades de la vida diaria en pacientes con enfermedad pulmonar obstructiva crónica: Validación d. Medicina Clínica, 129(9), 326-332. Retrieved from http:/ / external.doyma.es/pdf/2/2v129n09a13109543pdf001.pdf

Vu, K., \& Mitsunobu, F. (2005a). Five year observation of the effects of spa therapy for patients with pulmonary emphysema, evaluated by \%low attenuation area (\%LAA) of the lungs on high-resolution CT, \%Dlco and \%residual volume (RV). Alternative and Complementary Therapies, 11(2), 89-93.

$\mathrm{Vu}, \mathrm{K} .$, \& Mitsunobu, F. (2005b). Spa therapy for chronic obstructive pulmonary disease. Studies at the Misasa medical center. Alternative \& Complementary Therapies, (April), 89-93.

Wadell, K., Sundelin, G., Henriksson-Larsen, K., \& Rune Lundgren. (2004). High intensity physical group training in water - an effective training modality for patients with COPD. Respiratory Medicine, 98, 428-438.

Wadell, K., Henriksson-Larsen, K., Lundgren, R., \& Sundelin, G. (2005a). Group training in patients with COPD - long- term effects after decreased training frequency. Disability and Rehabilitation, 27(10), 571-581. doi:10.1080/09638280400018627

Wadell, K., Sundelin, F., Lundgren, R., Henriksson-Larsén, K., \& Lindström, B. (2005b). Muscle performance in patients with chronic obstructive pulmonary disease effects of a physical training programme. Advances in Physiotherapy, 7, 51-59.

Weiner P, Magadle R, Beckerman M, Weiner M, \& Berar-Yanay N. (2003). Specific expiratory muscle training in COPD. Chest, 124(2), 468-473.

White, A. J., Gompertz, S., \& Stockley, R. A. (2003). Chronic obstructive pulmonary disease . 6: The aetiology of exacerbations of chronic obstructive pulmonary disease. Thorax, 58(1), 73-80.

Wijkstra, P. J., Ten Vergert, E. M., van Altena, R., Otten, V., Kraan, J., Postma, D. S., et al. (1995). Long term benefits of rehabilitation at home on quality of life and exercise tolerance in patients with chronic obstructive pulmonary disease. Thorax, 50(8), 824-828. 
Yohannes, A. M., Baldwin, R. C., \& Connolly, M. J. (2005). Predictors of 1-year mortality in patients discharged from hospital following acute exacerbation of chronic obstructive pulmonary disease. Age and Ageing, 34(5), 491-496. doi:10.1093/ageing/afi163 


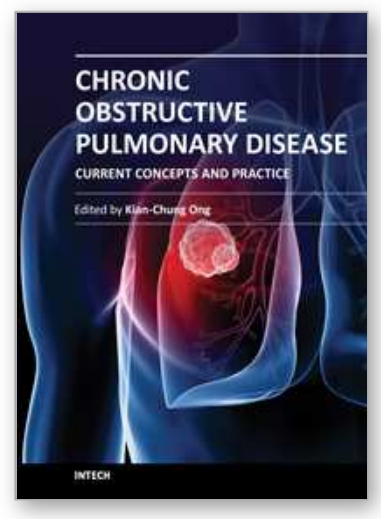

\author{
Chronic Obstructive Pulmonary Disease - Current Concepts and \\ Practice \\ Edited by Dr. Kian-Chung Ong
}

ISBN 978-953-51-0163-5

Hard cover, 474 pages

Publisher InTech

Published online 02, March, 2012

Published in print edition March, 2012

A decade or so ago, many clinicians were described as having an unnecessarily 'nihilistic' view of COPD. This has certainly changed over the years... This open access book on COPD provides a platform for scientists and clinicians from around the world to present their knowledge of the disease and up-to-date scientific findings, and avails the reader to a multitude of topics: from recent discoveries in the basic sciences to state-of-the-art interventions on COPD. Management of patients with COPD challenges the whole gamut of Respiratory Medicine - necessarily pushing frontiers in pulmonary function (and exercise) testing, radiologic imaging, pharmaceuticals, chest physiotherapy, intensive care with respiratory therapy, bronchology and thoracic surgery. In addition, multi-disciplinary inputs from other specialty fields such as cardiology, neuro-psychiatry, geriatric medicine and palliative care are often necessary for the comprehensive management of COPD. The recent progress and a multi-disciplinary approach in dealing with COPD certainly bode well for the future. Nonetheless, the final goal and ultimate outcome is in improving the health status and survival of patients with COPD.

\title{
How to reference
}

In order to correctly reference this scholarly work, feel free to copy and paste the following:

R. Martín-Valero, A. I. Cuesta-Vargas and M. T. Labajos-Manzanares (2012). Types of Physical Exercise Training for COPD Patients, Chronic Obstructive Pulmonary Disease - Current Concepts and Practice, Dr. Kian-Chung Ong (Ed.), ISBN: 978-953-51-0163-5, InTech, Available from:

http://www.intechopen.com/books/chronic-obstructive-pulmonary-disease-current-concepts-andpractice/types-of-physical-exercise-training-for-copd-patients

\section{INTECH}

open science | open minds

\section{InTech Europe}

University Campus STeP Ri

Slavka Krautzeka 83/A

51000 Rijeka, Croatia

Phone: +385 (51) 770447

Fax: +385 (51) 686166

www.intechopen.com

\section{InTech China}

Unit 405, Office Block, Hotel Equatorial Shanghai

No.65, Yan An Road (West), Shanghai, 200040, China

中国上海市延安西路65号上海国际贵都大饭店办公楼405单元

Phone: +86-21-62489820

Fax: +86-21-62489821 
(C) 2012 The Author(s). Licensee IntechOpen. This is an open access article distributed under the terms of the Creative Commons Attribution 3.0 License, which permits unrestricted use, distribution, and reproduction in any medium, provided the original work is properly cited. 